我們䁌做另外一系列的許多試騟，在這些試 数复, 都利用了一個技術。这個技街就是應用一

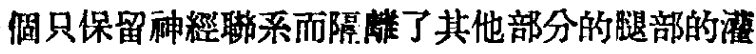
輸裝管。在右頸氣管分枝處和胸管各作了瘦管, 把全部淋巴産物放到生物體外去。

這樣，我們就可以指出，抗體的出動，是由 所有的淋巴組織所做的。

至於談到吞唡制激的物質是如何座生的，我 們的研究指出, 所有的富於絧狀队佊組織的器官

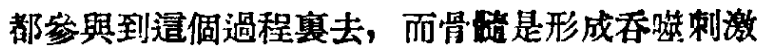
物質的最重要的器官。

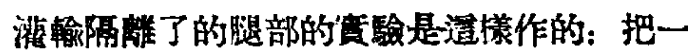
隻狗的腿部的循環系統和身體隔離, 但是保留完 整的坐骨神經。逼隻狗的血液供給是由另一隻狗 的经動脈和頸靜胍與造隻狗腿的動静脈聯系而循

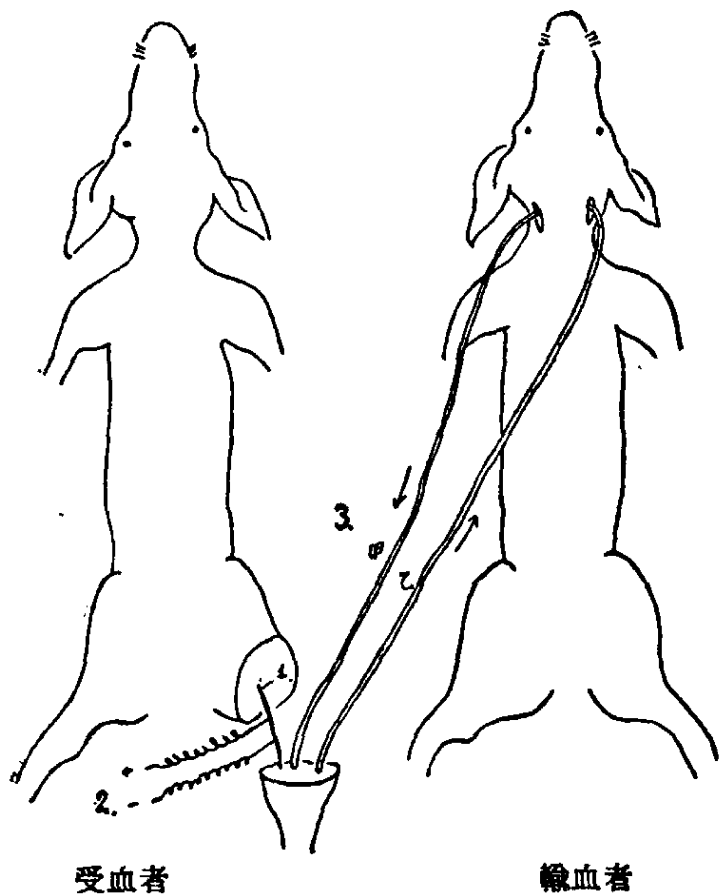

圆四腿部隔離與灌輸裝置

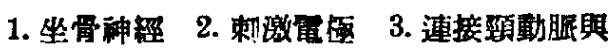

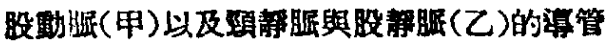

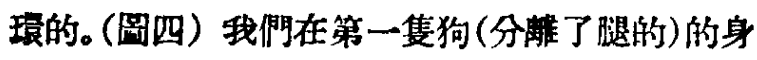

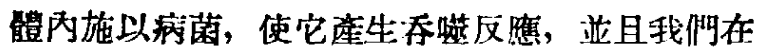

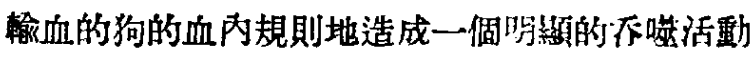
的高潮。

仔細的分析後，我們可以說暗個效果是由於

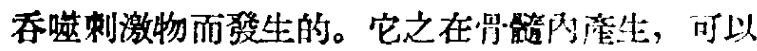
在脛骨的靜眼內證賽。同樣地，在用電剌湤了坐

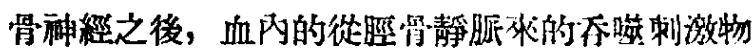
就增加 500-800\%。

造样, 我們可以看出造是第一一次我們可以談 到神經的忝哑刺激作用。在我們的工作的最後一 部分中, 我們研究了大腦皮質在生物㣻疫過程赛

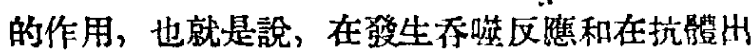
動上的作用。在這個目的上，我們聯系了一個特 殊的興套活動, 就是說鈴馨與施用疗葆聯系起來。

一個月之後，只要鈴馨一響，由於條件反射的機 構，在這個詰驗裏所有的狗（6隻）身上我門都 得到 200-300\% 的乔哑反應和一次抗體的出動。

12 年来的研究, 總結出在生物琶疾的過 程

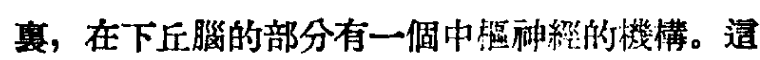
機構能使所有的預先仔在的保護方法活動起來。

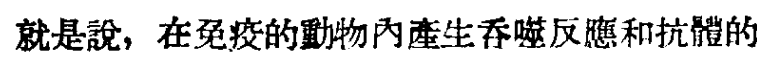
出動。

大腦皮雷也能參與到這個機構裹。可是'它的 参與不是必須的，因此，我椚看到，在生物免

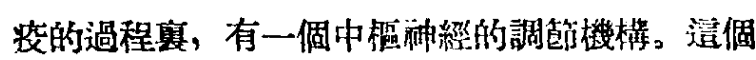
機構可以認第是機體對於㻴境裹生物因絭變化的 適應的生理反應, 這些反應和對物理团絭的適應

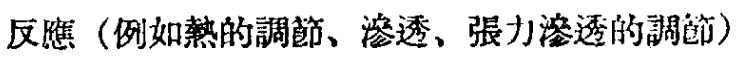
是完全相似的。我們的砷究的結果是在世求洛夫 的新的概念範園赛。根據他的概念, 中秒㬏經系 梳在所有的器官活動的調協與和諧上起了很重要 的作用的。在機體對外界環境的䢛㫿上,也起了很 重要的作用。

\title{
“辟爾當 人”的秘密
}

辟爾當人 (Piltdownman) 或道生 氏暗人 (Dawson's downman) 曾否员正存在罜一問 题，是四十餘年來人類進化史上的一件疑案，㯰

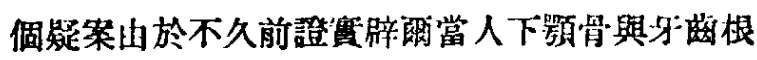
本是傦造的而得到了解决。英國工人日報於 1953 年11月23日、24日報道了這件事情。 
1911年在英國苦克斯 (Sussex) 州辟爾當 (Piltdown)地方一個探磁石的砂礠坑中, 發現 了一件狀似楖子的東西, 這束西當時傳到了對化 石極感興趣的律師查理 - 道生手中, 經他鑑定, 認 第是原始人類的頭滥骨。隨後, 道生又與英國博 物館“古生物學家”伍德華在同一地方發現了一塊

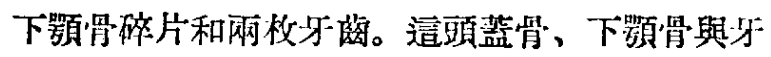

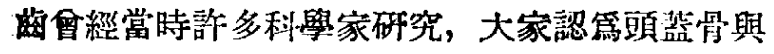
現代人極相似, 腦量有 1,500 立方厘米, 䢹下顎 骨的許多特徵（如完全無㑑部）却又與現代猩猖 相似。因此引起了很大的争論, 有人主張這䫒蓋 骯與下顎骨同屬於一個人, 有人反對這個主張, 而道生則堅决認篇它們问凰於一個極篇原始的 人, 亚把這種原始人命名篇道生氏睰人。後來, 在1915年距最初發現地2-3公里的地方, 又發現 了一塊頭蓝骨碎片和一故曰菌, 經過詳細考察後, 登明與以前所弡現的完全相似。到㞄時, 這個疑 案似乎已經完全解决。

然而, 牛津大學與英國博物館的科學傢們不 久以前利用最新的技街再加以研究後, 終於揭穿

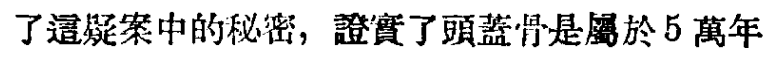
前的原始人類所有, 而下顎骨却是閏 於現 代猩 猩的, 祇是由於處心皘虑的作愁, 外觀才變得好像 北石一樣而已。原來, 道生篇了使兩件東西顏色 一样，篔把它們用重鉻酸鉀庭理過。關於造點， 道生本人也是承認的。在伍德華的著作“最早的英

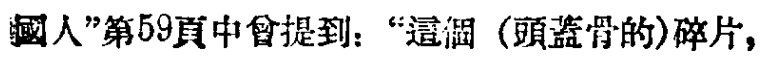

在道生繁以第可以增加其强度而淁入重鉻酸鉡溶

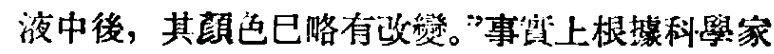
們的證明，下顎骨也會用重鉻酸鍀塎液浸過，踓 然伍德華說他没有允訐遭樣作。

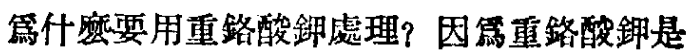

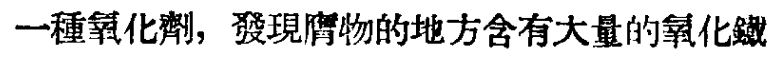

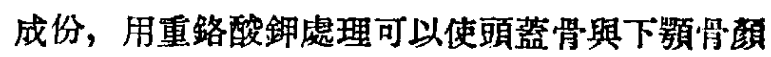
色一致。

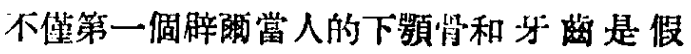
的，1915年發現的一片頙蓝骨碎片和一枚牙遥也 是假的。网片頭泴骨中僅一片是椇的化石, 而另 一片則比較接近現代；第了使它與第一片相似， 第二片曾經過人工着色。據說1915年㻐現的牙 上也有人工擦傷的痕跡。

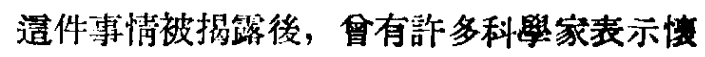
疑, 然而揭穿剧酮當人臨局的三個科學家之 一一一歐克萊博士一一令人信服地指出, 由於科 學的進步, 迄今少無法檢驗的標本, 已緃有可能 來检驗了。

辟爾當人是真是假的問題終於解决了。在远

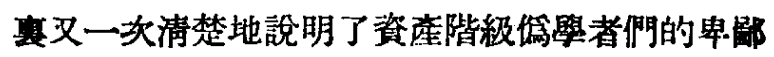
無恥，他們篇了個人名利，不情掄造“科學”根 譃, 揘造出一個不倫不類的腦子很张達而下影又 十分原始的辟爾當人來, 但其結果祇不過篇人 噪而巳。

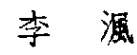

（復且大雿） 